\title{
Assessment of Negative Factors Affecting the Intestinal Microbiota in People with Excessive Body Mass Compared to People with Normal Body Mass ${ }^{\dagger}$
}

\author{
Karolina Osowiecka ${ }^{1}$, Natalia Pokorna ${ }^{2}$ and Damian Skrypnik ${ }^{3}$ \\ 1 Department of Dietetics, Institute of Human Nutrition Sciences, Warsaw University of Life Sciences, \\ Warsaw, Poland; \\ 2 Institute of Human Nutrition and Dietetics, Faculty of Food Science and Nutrition, Poznan University of \\ Life Sciences, Poznan, Poland; pokorna.natalia@wp.pl \\ 3 Department of Treatment of Obesity, Metabolic Disorders and Clinical Dietetics, Poznan University of \\ Medical Sciences, Poznan, Poland; damian.skrypnik@gmail.com \\ * Correspondence: osowiecka.karolina@wp.pl \\ + Presented at the The 1st International Electronic Conference on Nutrients - Nutritional and Microbiota \\ Effects on Chronic Disease, 2-15 November 2020; Available online: https://iecn2020.sciforum.net/. \\ Published: 30 October 2020
}

\begin{abstract}
Rationale: Intestinal microbiota plays a significant role in the human body. A range of negative factors may lead to dysbiosis, which results in many diseases (e.g., cancer) and metabolic disorders. It has been shown that people with a body mass index (BMI) of $\geq 25 \mathrm{~kg} / \mathrm{m}^{2}$ present diminished microbial diversity. Additional negative factors such as stress, the use of non-steroidal anti-inflammatory drugs (NSAID) and proton pomp inhibitors (PPI) may result in greater dysbiosis compared to people with normal body mass. The aim of the study was to compare the incidence of negative factors affecting the intestinal microbiota in people with excessive body mass vs. people with normal body mass. Methods: The study involved volunteers aged $18-65$ years: 582 people with normal BMI $\left(18.5-24.99 \mathrm{~kg} / \mathrm{m}^{2}\right)$ and 538 people with BMI $\geq 25 \mathrm{~kg} / \mathrm{m}^{2}$. The study was conducted using the author's survey by the Computer-Assisted Web Interviewing method. The survey included the questions on sociodemographic features, level of physical activity, frequency of smoking, and stress. Frequency of NSAID and PPI use was also investigated. BMI was used to assess nutritional status. For statistics the Fisher test was implemented. $p$-Value $<0.05$ was considered significant. Results: Women predominated in the study $(p<0.0001)$. People with normal BMI had a significantly higher level of physical activity $(p<0.0001)$ and smoked less $(p=0.0356)$. People with excessive body mass were less likely to report illness ( $p=0.0004)$, but more often they took PPI $(p=0.0337)$. Conclusions: People with BMI $\geq 25 \mathrm{~kg} / \mathrm{m}^{2}$ present more factors which may result in dysbiosis and lead to dysbiosis-related health problems in future compared to people with normal BMI.
\end{abstract}

Keywords: dysbiosis; excessive body mass; health effects; microbiota; obesity

\section{Introduction}

It is estimated that the number of microorganisms in the digestive tract is over $10^{14} \mathrm{CFU}$ (colony forming units), forming microbiota. The intestinal microbiota plays a significant role in the human body, for example by shaping the intestinal epithelium, protecting against pathogens, and regulating the host's immunity [1]. A range of negative factors may promote dysbiosis, which leads to many diseases (e.g., cancer) and metabolic disorders [2]. It has been shown that people with a body mass index (BMI) of $\geq 25 \mathrm{~kg} / \mathrm{m}^{2}$ present diminished microbial diversity. Additional negative factors such as alcohol consumption [3], stress [4], sedentary lifestyle [5], and smoking cigarettes [6] may decrease 
the quality of microbiota. Also use of non-steroidal anti-inflammatory drugs (NSAID) [7] and proton pomp inhibitors (PPI) [8] may result in greater dysbiosis. The mechanism linking the microbiota quality and PPIs/NSAIDs is not fully understood. PPIs are believed to reduce the amount of hydrochloric acid in the stomach, which allows the entry of harmful bacteria [9]. The use of NSAIDs may reduce the composition of the gut microbiota and mainly cause an overgrowth of gram-negative and anaerobic bacteria. Thus, it weakens the mucosal defenses and increases the susceptibility to intestinal damage [10]. The aim of the study was to compare the incidence of negative factors affecting the intestinal microbiota in people with excessive body mass vs. people with normal body mass.

\section{Materials and Methods}

The survey was attended by Polish volunteers aged $18-65$ years. The subjects $(n=1120)$ were divided into 2 groups: subjects with normal BMI "N-BMI group" (BMI 18.5-24.99 kg/m²) (n = 582) and with excessive BMI "E-BMI group" (BMI $\geq 25 \mathrm{~kg} / \mathrm{m}^{2}=$ pre-obesity and obesity) ( $\mathrm{n}=538$ ) (according to the criteria recognized by WHO, World Health Organization) [11]. The study was conducted with the use of the original survey using the Computer-Assisted Web Interviewing method. The CAWI method is a popular method of data collection. It is characterized by the creation of an online research questionnaire that is displayed to interested respondents. It is an easy and cheap way to reach a research group who will complete the survey on their own [12]. The surveys were collected between February and June 2020. The questionnaire included questions on sociodemographic characteristics, level of physical activity, frequency of smoking, and stress. Also the frequency of use of NSAIDs and PPIs was examined. Statistica for Windows 10.0 software (StatSoft, Kraków, Poland) was used to analyze the results. For statistics the Fisher test was implemented. $p$-Value $<0.05$ was considered significant.

\section{Results}

Both groups aged 18-65 were dominated by women $(p<0.0001)$. The mean age for the N-BMI group was $32.6 \pm 8.6$ years, and for the group with excessive body weight $35.97 \pm 9.6$ years. The main age in the groups differed significantly $(p<0.0001)$. The participants of the research declared an average or good financial situation. This feature differed significantly between the groups $(p=0.0137)$ (Table 1).

Table 1. Characteristics of group $(n=1120)$.

\begin{tabular}{ccc}
\hline Characteristics of Group & E-BMI Group $(\mathbf{n}=\mathbf{5 3 8}) \mathbf{( \% )}$ & N-BMI Group (n = 582) (\%) \\
\hline \multicolumn{3}{c}{ Gender } \\
\hline Female & $474(88.1)$ & $553(95)$ \\
\hline Male & $64(11.9)$ & $29(5)$ \\
\hline \multicolumn{3}{c}{ Age (years) } \\
\hline $18-24$ & $50(9.3)$ & $101(17.4)$ \\
\hline $25-34$ & $218(40.5)$ & $279(47.9)$ \\
\hline $35-44$ & $169(31.4)$ & $149(25.6)$ \\
\hline $45-54$ & $72(13.4)$ & $36(6.2)$ \\
\hline $55-65$ & $29(5.4)$ & $17(2.9)$ \\
\hline \multicolumn{3}{c}{ Education level } \\
\hline Primary & $5(0.9)$ & $7(1.2)$ \\
\hline Lower secondary & $24(4.5)$ & $18(3.1)$ \\
\hline Upper secondary & $136(25.3)$ & $71(19.6)$ \\
\hline Student & $45(8.4)$ & $348(59.8)$ \\
\hline Higher & $308(57.2)$ & $5(0.9)$ \\
\hline PhD Student & $4(0.7)$ \\
\hline PhD or higher & $16(3)$ \\
\hline
\end{tabular}




\begin{tabular}{ccc}
\hline Very Bad & $8(1.5)$ & $3(0.5)$ \\
\hline Bad & $13(2.4)$ & $20(3.4)$ \\
\hline Moderate & $253(47)$ & $232(39.9)$ \\
\hline Good & $214(39.8)$ & $282(48.5)$ \\
\hline Very good & $50(9.3)$ & $45(7.7)$ \\
\hline
\end{tabular}

The N-BMI group differed significantly from the overweight group in the range of assessing own level of physical activity $(p<0.0001)$, and frequency of smoking $(p=0.0356)$ (Table 2$)$. Most often, participants declared moderate physical activity, almost $50 \%$ had a sedentary level (E-BMI group) or approximately $30 \%$ (N-BMI group). In contrast, the frequency of alcohol consumption and stress were similar between the groups. The presence or the lack of diagnosis of the disease also significantly differed and the N-BMI group was diagnosed in approximately $11 \%$. The use of NSAIDs was declared by 456 people (E-BMI group) and 481 (N-BMI group). In both groups, the most common use of NSAIDs was from less than once a month to several times a month. There was no significant difference between the groups ( $p=0.3737$ ) in NSAIDs use. On the other hand, PPI drugs were taken by 140 people in E-BMI group and 110 in N-BMI group. PPIs were most often taken once a day. In this range significant difference was noticed $(p=0.0050)$ (Table 2$)$.

Table 2. Selected factors influencing the microbiota $(n=1120)$.

\begin{tabular}{|c|c|c|c|}
\hline & E-BMI $(n=538)(\%)$ & N-BMI $(n=582)(\%)$ & $p$-Value \\
\hline \multicolumn{4}{|c|}{ Level of physical activity } \\
\hline Sedentary & $239(44.4)$ & $177(30.4)$ & \multirow{3}{*}{$<0.0001$} \\
\hline Moderate & $273(50.8)$ & $345(59.3)$ & \\
\hline High & $26(4.8)$ & $60(10.3)$ & \\
\hline \multicolumn{4}{|c|}{ Cigarette smoking } \\
\hline Not smoking & $324(60.2)$ & $393(67.6)$ & \multirow{5}{*}{0.0356} \\
\hline Has smoked in the past & $92(17.1)$ & $81(13.9)$ & \\
\hline$<5$ cigarettes a day & $30(5.6)$ & $28(4.8)$ & \\
\hline 5-20 cigarettes a day & $83(15.4)$ & $78(13.4)$ & \\
\hline$>20$ cigarettes a day & $9(1.7)$ & $2(0.3)$ & \\
\hline \multicolumn{4}{|c|}{ Alcohol } \\
\hline $\mathrm{No}$ & $184(34.2)$ & $220(37.8)$ & \multirow{5}{*}{0.4440} \\
\hline Less often than once a week & $213(39.6)$ & $237(40.7)$ & \\
\hline 1-2 times a week & $106(19.7)$ & $94(16.2)$ & \\
\hline 3-4 times a week & $27(5)$ & $24(4.1)$ & \\
\hline 5 times a week or more & $8(1.5)$ & $7(1.2)$ & \\
\hline \multicolumn{4}{|c|}{ Stress } \\
\hline No & $22(4.1)$ & $24(4.1)$ & \multirow{5}{*}{0.2259} \\
\hline Less often than once a week & $104(19.3)$ & $137(23.5)$ & \\
\hline 1-2 times a week & $148(27.5)$ & $174(29.9)$ & \\
\hline 3-4 times a week & $130(24.2)$ & $118(20.3)$ & \\
\hline 5 times a week or more & $134(24.9)$ & $129(22.2)$ & \\
\hline \multicolumn{4}{|c|}{ Diagnosis of the disease } \\
\hline Not diagnosed & $350(60.1)$ & $289(49.7)$ & \multirow{2}{*}{0.0004} \\
\hline Diagnosed & $232(39.9)$ & $293(50.3)$ & \\
\hline \multicolumn{4}{|c|}{ NSAID drugs } \\
\hline I do not take & $82(15.2)$ & $101(17.4)$ & \multirow{5}{*}{0.2580} \\
\hline Once a month or less & $194(36.1)$ & $223(38.1)$ & \\
\hline Few times a month & $171(31.9)$ & $175(30.1)$ & \\
\hline Once a week & $25(4.6)$ & $26(4.5)$ & \\
\hline Few times a week & $43(8)$ & $33(5.7)$ & \\
\hline
\end{tabular}




\begin{tabular}{ccc}
\hline Once a day & $18(3.3)$ & $12(2.1)$ \\
\hline More than once a day & $5(0.9)$ & $12(2.1)$ \\
\hline & PPI drugs & \\
\hline I do not take & $398(74)$ & $472(81.1)$ \\
\hline Once a month or less & $40(7.4)$ & $32(5.5)$ \\
\hline Few times a month & $27(5)$ & $21(3.6)$ \\
\hline Once a week & $4(0.7)$ & $2(0.3)$ \\
\hline Few times a week & $12(2.2)$ & $11(1.9)$ \\
\hline Once a day & $53(10)$ & $34(5.9)$ \\
\hline More than once a day & $4(0.7)$ & $10(1.7)$ \\
\hline
\end{tabular}

\section{Discussion}

In a Polish study of Słaby et al. assessing, inter alia, intake of NSAID drugs and knowledge about probiotics, the number of women compared to men also dominated (79.4\% versus $20.6 \%$ ). Most people were over 61 years of age $(28.9 \%)$ and between $26-40$ years of age $(23.5 \%)$-thus, older than in the own study [7]. A study of Bressa et al. showed differences in the profile of the gut microbiota between women with an active lifestyle compared to a sedentary lifestyle. They proved that performing physical exercise for at least $3 \mathrm{~h}$ a week resulted in a greater number of pro-health bacterial species, including Faecalibacterium prausnitzii, Akkermansia muciniphila [5]. Referring to smoking cigarettes - Lee et al. found that microbiota diversity differed between current smokers and non-smokers in a cross-sectional population study $(p=0.017)$ and smokers $(p=0.011)$. The authors found no significant difference between non-smokers and previous cigarette smokers [6]. Moderate alcohol consumption, including short-term consumption, may contribute to dysbiosis (e.g., by reducing the number of Lactobacillus) in rats [3]. There are several factors by which stress can adversely affect the microbiota. These include, among others: change in gastrointestinal motility and reduced digestive activity, and thus the availability of the substrates. Also, the stress changes immune function, causes oxidative stress and inflammation [4]. In the study by Słaby et al. $31 \%$ of the respondents declared taking NSAIDs, which is lower than in the own study-in both groups [7]. In a study of Imhann et al. among 1815 participants, only 211 (11.6\%) used PPIs, which is less than in the own study. In the group of this 211 patients, the authors observed a significant increase in the number of bacteria: Enterococcus, Streptococcus, Staphylococcus and potentially pathogenic Escherichia coli [8].

\section{Conlusions}

People with BMI $\geq 25 \mathrm{~kg} / \mathrm{m}^{2}$ present more factors which may result in dysbiosis and lead to dysbiosis-related health problems compared to people with normal BMI.

Author Contributions: Conceptualization, K.O., N.P. and D.S.; methodology, K.O., N.P. and D.S.; software, D.S.; validation, K.O. and N.P.; formal analysis, K.O, N.P. and D.S; investigation, K.O. and N.P.; data curation, K.O.; writing-original draft preparation, K.O. and N.P.; writing-review and editing, D.S.; visualization, K.O and N.P.; supervision, D.S.; project administration, K.O. All authors have read and agreed to the published version of the manuscript.

Acknowledgments: The authors kindly thank all respondents for their participation in the study.

Conflicts of Interest: The authors declare no conflict of interest.

\section{References}

1. Thursby, E.; Juge, N. Introduction to the human gut microbiota. Biochem. J. 2017, 474, 1823-1836.

2. DeGruttola, A.K.; Low, D.; Mizoguchi, A.; Mizoguchi, E. Current Understanding of Dysbiosis in Disease in Human and Animal Models. Inflamm. Bowel Dis. 2016, 22, 1137-1150.

3. Kosnicki, K.L.; Penprase, J.C.; Cintora, P.; Torres, P.J.; Harris, G.L.; Brasser, S.M.; Kelley, S.T. Effects of moderate, voluntary ethanol consumption on the rat and human gut microbiome. Addict. Biol. 2019, 24, $617-630$. 
4. Karl, J.P.; Hatch, A.M.; Arcidiacono, S.M.; Pearce, S.C.; Pantoja-Feliciano, I.G.; Doherty, L.A.; Soares, J.W. Effects of Psychological, Environmental and Physical Stressors on the Gut Microbiota. Front. Microbiol. 2018, 9, 2013.

5. Bressa, C.; Bailén-Andrino, M.; Pérez-Santiago, J.; González-Soltero, R.; Pérez, M.; Montalvo-Lominchar, M.G.; Maté-Muñoz, J.L.; Domínguez, R.; Moreno, D.; Larrosa, M. Differences in gut microbiota profile between women with active lifestyle and sedentary women. PLoS ONE 2017, 12, e0171352.

6. Lee, S.H.; Yun, Y.; Kim, S.J.; Lee, E.J.; Chang, Y.; Ryu, S.; Shin, H.; Kim, H.L.; Kim, H.N.; Lee, J.H. Association between Cigarette Smoking Status and Composition of Gut Microbiota: Population-Based Cross-Sectional Study. J. Clin. Med. 2018, 7, 282.

7. Słaby, D.; Szewczyk, S.; Beberok, A.; Wrześniok, D. The role of protective agents in pharmacotherapyAssessment of patients awareness [Rola preparatów osłonowych w farmakoterapii-Ocena świadomości pacjentów]. Farm Pol. 2019, 75, 591-598.

8. Imhann, F.; Bonder, M.J.; Vich Vila, A.; Fu, J.; Mujagic, Z.; Vork, L.; Tigchelaar, E.F.; Jankipersadsing, S.A.; Cenit, M.C.; Harmsen, H.J.; et al. Proton pump inhibitors affect the gut microbiome. Gut 2016, 65, 740-748.

9. Macke, L.; Schulz, C.; Koletzko, L.; Malfertheiner, P. Systematic review: The effects of proton pump inhibitors on the microbiome of the digestive tract-Evidence from next-generation sequencing studies. Aliment. Pharmacol. Ther. 2020, 51, 505-526.

10. Maseda, D.; Ricciotti, E. NSAID-Gut Microbiota Interactions. Front. Pharmacol. 2020, 11, 1153.

11. Database on Body Mass Index. Available online: http://www.euro.who.int/en/health-topics/diseaseprevention/nutrition/a-healthy-lifestyle/body-mass-index-bmi (accessed on 16 October 2020).

12. Sowa, P.; Pędziński, B.; Krzyżak, M.; Maślach, D.; Wójcik, S.; Szpak, A. The Computer-Assisted Web Interview Method as Used in the National Study of ICT Use in Primary Healthcare in Poland - Reflections on a Case Study. Stud. Log. Gramm. Rhetor. 2015, 43, 137-146.

Publisher's Note: MDPI stays neutral with regard to jurisdictional claims in published maps and institutional affiliations.

(C) 2020 by the authors. Submitted for possible open access publication under the terms and conditions of the Creative Commons Attribution (CC BY) license (http://creativecommons.org/licenses/by/4.0/). 